\title{
Assessment of climate change and associated impact on selected sectors in Poland
}

\author{
Zbigniew W. Kundzewicz ${ }^{1,4} \cdot$ Mikołaj Piniewski $^{3,4} \cdot$ Abdelkader Mezghani $^{2} \cdot$ Tomasz Okruszko $^{3} \cdot$ Iwona Pińskwar $^{1}$ (1) . \\ Ignacy Kardel ${ }^{3}$. Øystein $\mathrm{Hov}^{2} \cdot$ Mateusz Szcześniak ${ }^{3} \cdot$ Małgorzata Szwed $^{1} \cdot$ Rasmus E. Benestad $^{2}$. \\ Paweł Marcinkowski ${ }^{3}$ - Dariusz Graczyk ${ }^{1} \cdot$ Andreas Dobler $^{2}$ - Eirik J. Førland ${ }^{2} \cdot$ Joanna O'Keefe $^{3} \cdot$ Adam Choryński $^{1}$. \\ Kajsa M. Parding ${ }^{2}$ Jan Erik Haugen ${ }^{2}$
}

Received: 3 April 2018 / Accepted: 29 October 2018 / Published online: 3 November 2018

(C) The Author(s) 2018

\begin{abstract}
The present paper offers a brief assessment of climate change and associated impact in Poland, based on selected results of the Polish-Norwegian CHASE-PL project. Impacts are examined in selected sectors, such as water resources, natural hazard risk reduction, environment, agriculture and health. Results of change detection in long time series of observed climate and climate impact variables in Poland are presented. Also, projections of climate variability and change are provided for time horizons of 2021-2050 and 2071-2100 for two emission scenarios, RCP4.5 and RCP8.5 in comparison with control period, 1971-2000. Based on climate projections, examination of future impacts on sectors is also carried out. Selected uncertainty issues relevant to observations, understanding and projections are tackled as well.
\end{abstract}

Keywords Climate change $\cdot$ Climate change impact $\cdot$ Projections $\cdot$ Poland

\section{Introduction}

The topical area of climate change and associated impacts, recognized as very important in many European countries, does not generally get a high status in the public discourse in Poland. Generally, Poles are aware of climate change, but this topical area is not broadly considered as a high priority (Kundzewicz and Matczak 2012; Kundzewicz et al. 2017f). Observed climate change impacts are not dramatic, and the attribution of these impacts is rather complex, due to the existence of multiple driving factors. Public discourse is influenced by combination of strong natural variability of hydro-meteorological phenomena and significant

Iwona Pińskwar

iwona.pinskwar@isrl.poznan.pl

1 Institute for Agricultural and Forest Environment of the Polish Academy of Sciences, Poznan, Poland

2 Norwegian Meteorological Institute (Met Norway), Oslo, Norway

3 Warsaw University of Life Sciences (SGGW), Warsaw, Poland

4 Potsdam Institute for Climate Impact Research (PIK), Potsdam, Germany uncertainty of projections for the future. Consequently, adaptation to climate change is not taken as such a serious issue as it deserves. Mitigation policy is even more challenged, because the public perception is driven by the deeply rooted wisdom that Poland "sits on coal" and coal guarantees the national energy security. The carbon footprint per inhabitant and per unit GDP in Poland has been high (Ceglarz et al. 2018).

The present paper offers a review of selected results generated within the CHASE-PL (Climate change impact assessment for selected sectors in Poland) project, carried out in 2014-2017, within the framework of the Polish-Norwegian Research Programme under the Norwegian Financial Mechanism. The CHASE-PL project aimed to provide substantial intellectual support for counteracting climate change and its adverse impacts in Poland, hence potentially contributing to sustainable economic development and environmental protection. The CHASE-PL project was jointly implemented by three institutional partners of the project consortium (Institute for Agricultural and Forest Environment of the Polish Academy of Sciences, Poznań, Poland; Norwegian Meteorological Institute, Oslo, Norway; and Warsaw University of Life Sciences, Warsaw, Poland). The research topics tackled in the project were the following: 
- Detection of change in observation records of climate and climate impact variables;

- Projections of climate variability and change for the future;

- Model-based assessment of climate change impact;

- Index-based assessment of climate change impacts on agriculture and ecosystems;

- Uncertainty in understanding, observations and projections-a system framework.

The present paper is organized as follows. After discussion of observations and projections of climate change, climate change impacts in selected areas are tackled, and finally—uncertainty and perception issues are discussed.

\section{Change detection in observed climate data}

Change detection in observation records of climatic variables in Poland was carried out for a range of variables of particular relevance and interest, such as temperature (Graczyk et al. 2017), mean precipitation (Pińskwar et al. 2018b; Szwed 2018), as well as intense precipitation (Pińskwar et al. 2018a) and snow cover (Szwed et al. 2017).

Figure 1 summarizes changes in mean annual temperature and precipitation in Poland for the time interval 1961-2017. The positive trend in temperature is well visible, even if deviations from the trend in particular years are quite large. For precipitation, the trend is weak and inter-annual and inter-decadal variability is dominating.

\section{Temperature}

Graczyk et al. (2017) examined observed changes in several "hot" indices, based on temperature observation records collected at 60 meteorological stations in Poland. Values of multiple indices associated with heat waves were determined. Among the indices were: the duration of the longest hot spell, the number of hot days $\left(T_{\max } \geq 30^{\circ} \mathrm{C}\right)$, the number of extremely hot days $\left(T_{\max } \geq 35^{\circ} \mathrm{C}\right)$, as well as the number of tropical nights $\left(T_{\min } \geq 20^{\circ} \mathrm{C}\right)$ in the year. The same authors analyzed also the spatial distribution of change in indices, with the help of the Mann-Kendall test, as well as the significance level of the resultant trends. Values of indices for the 1991-2013 interval were examined and compared to the reference period, 1961-1990. The increase was detected for most indices at the 5\% significance level, for many examined stations. Graczyk et al. (2017) found statistically significant increasing trends in three variables: the number of hot days and the duration of the longest hot spell in summer, as well as the number of tropical nights in a year, for most of the data. In 1961-1990, the longest duration of hot spell reached 10 days, while in 1991-2013, several longer hot spells, up to the duration of 17 days, were recorded.

\section{Precipitation}

Pińskwar et al. (2018b) examined changes in values of indices of observed mean precipitation, based on a set of daily precipitation records for 45 stations in Poland, most of which spanned over the interval 1951-2017. They examined changes in annual, semi-annual, seasonal and monthly precipitation totals, as well as in the number of days with daily precipitation equal to or greater than $1 \mathrm{~mm}$, and in the SDII (Simple Daily Intensity Index) and in the ratio of precipitation in the summer half-year (April-September) to precipitation in the winter half-year (October-March). Many changes were detected, most of which were statistically insignificant, at the $10 \%$ level. Yet, regionally consistent seasonal changes
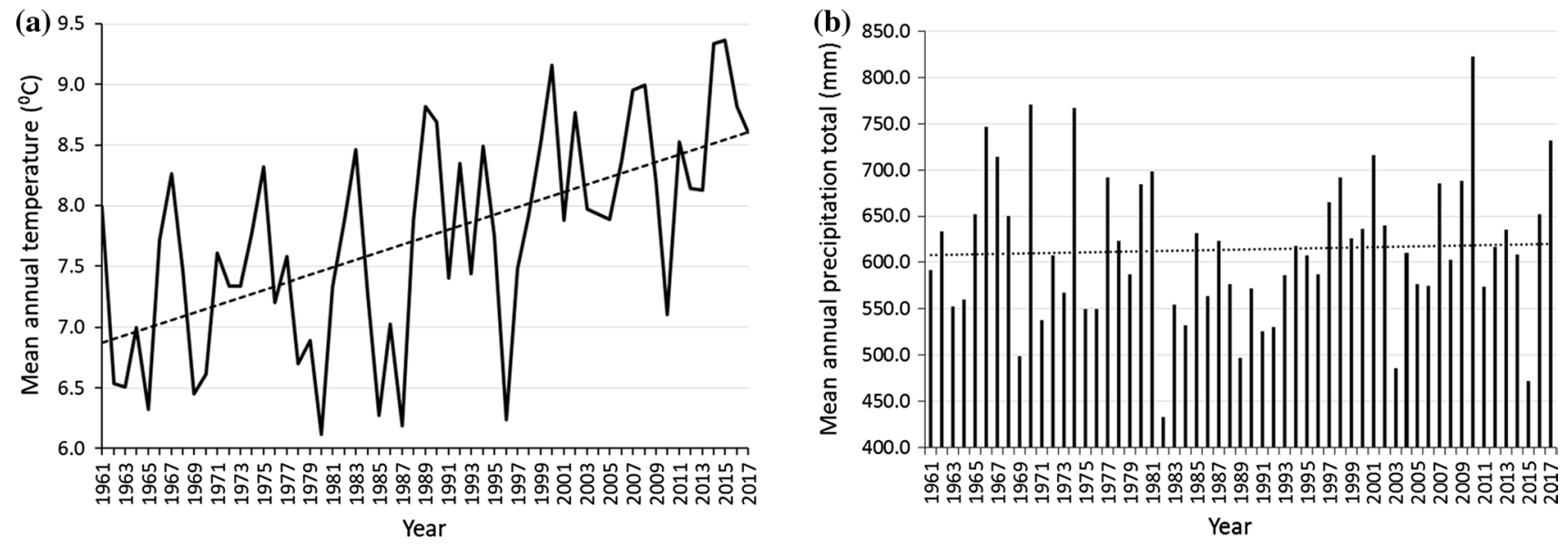

Fig. 1 Observed mean annual a temperature and b precipitation in Poland. Temperature diagram illustrates a mean of 60 stations. Precipitation diagram illustrates the annual mean at 42 stations situated at the altitude below $400 \mathrm{~m}$ a.s.l. Dotted lines indicate trends 
were also found, with dominating precipitation increase in spring and winter.

Szwed (2018) examined observed precipitation changes, tackling their spatial and temporal (seasonal) distribution and spotted a slight increase in annual precipitation. A stronger increase was noted in the northern part of Poland. Based on the precipitation unevenness index, an intra-year variability precipitation on the country territory can be defined as moderate and rather unevenly distributed. However, no statistically significant (at 5\% level) changes in the mean were found for 1951-2013. The most variable monthly precipitation was recorded in July and June, while the most stable-from January to March. The share of June-July precipitation can reach more than $40 \%$ of the annual precipitation total, while the share of winter months-no more than a dozen or so percent each. The most visible increases in the monthly precipitation totals as well as in the share of monthly precipitation within the annual total were found during the colder half-year, especially in March, with statistically significant trend detected for several stations in the northern and central parts of Poland.

\section{Extreme precipitation}

Pińskwar et al. (2018a) noted the occurrence of many episodes of extreme precipitation excess and deficit in Europe and in Poland in recent decades that had caused considerable, and adverse, economic and social impacts. In Poland, the changes in values of climate indices were found to exhibit complex, spatial and temporal, variability. Pińskwar et al. (2018a) analyzed changes in such indices of observation records as: maximum seasonal $24 \mathrm{~h}$ precipitation for winter and summer half-years; maximum 5-day precipitation; maximum monthly precipitation; as well as the number of days with intense or very intense precipitation (with daily rate in excess of, respectively, $10 \mathrm{~mm}$ or $20 \mathrm{~mm}$ ). Also, the maximum number of consecutive dry days (defined as those with daily precipitation below $1 \mathrm{~mm}$ ) in the summer half-year was analyzed. Examination of precipitation extremes showed that maximum 24-h precipitation for the summer half-year as well as 5-day and monthly precipitation sums increased for many stations. The number of days with intense precipitation was also found to increase especially in the northwestern part of Poland, while the increase in the number of consecutive dry days was noted for many stations in the summer half-year. Comparison of the 1961-1990 interval and the later, warmer, 1991-2015 interval revealed that during the last 25 years most statistical precipitation indices (25th and 75th percentiles, median, mean and maximum) were higher than in 30 years before. However, most changes detected by Pińskwar et al. (2018a) were statistically insignificant. Yet, it is interesting to note that some of these results contradict the findings of other authors (see discussion in Pińskwar et al. (2018a) and Łupikasza (2010)) that had been based on earlier observation records that do not include the recent interval, 2007-2015. However, a study by Łupikasza (2017) with data records extending to February 2008 and for several stations to 2015, showed increasing trends especially for spring and during winter in the northern part of Poland. The predominant decreasing trends during summer and autumn were also detected in the study.

\section{Snow}

Szwed et al. (2017) examined the variability of such snow cover characteristics in Poland as: snow depth, number of days with snow cover and dates of the beginning and the end of snow cover. A set of 43 long time series of station observation records in the country in 1952-2013 were used for change detection. Trends in analyzed data were sought, with the help of the Mann-Kendall test. In order to interpret temporal changes in snow cover characteristics, the intervals of 1952-1990 and of 1991-2013 were compared. However, the observed behavior of snow-related variables was found to be complex and difficult to interpret. Among the potential reasons was the location of Poland in the zone of transitional moderate climate, which is known for strong climate variability. It was possible to find statistical links between the North Atlantic Oscillation (NAO) index and such snow characteristics in Poland, as the snow depth and the number of snow cover days.

\section{Climate projections}

Projections of climate variability and change in Poland were obtained with the help of downscaling of General Circulation Models (GCMs) simulations for future conditions. All analyses of model-based projections in the CHASEPL project were carried out with the ensemble of climate projections comprising nine regional climate model outputs (bias-corrected and downscaled to a $5 \mathrm{~km} \times 5 \mathrm{~km}$ grid) stemming from the EURO-CORDEX ensemble for two future time horizons: near future, 2021-2050 and far future, 2071-2100. The two so-called representative concentration pathways (associated greenhouse gas emission scenarios) RCP4.5 (intermediate emissions) and RCP8.5 (high emissions) were assumed. Simulations for the historical control period, 1971-2000, were used for comparison. Quantilemapping method was applied to correct for systematic seasonal biases in simulations before assessing the changes in annual and seasonal means of precipitation and temperature over Poland.

Mezghani et al. (2016) compiled and published the CHASE-PL climate projections-gridded daily precipitation and temperature-5 km (CPLCP-GDPT5) dataset, 
comprising projected daily minimum and maximum values of air temperature as well as of precipitation totals. Projected changes for Poland, estimated from the multi-model ensemble, showed that annual temperature mean is expected to increase by approximately $1{ }^{\circ} \mathrm{C}$ until $2021-2050$ and by about $2{ }^{\circ} \mathrm{C}$ until $2071-2100$, under the RCP4.5 scenario. Under assumption of the RCP8.5 scenario, the warming was projected to increase to almost $4{ }^{\circ} \mathrm{C}$ by the $2071-2100$ horizon. Also, likely increase in regional annual precipitation is projected, being of the order of $6-10 \%$ and $8-16 \%$, respectively, for the near and remote future horizon. Individual model simulations reflected warmer and wetter conditions on the annual scale. The magnitude of change was found to be higher in the far future than in the near future. The same statement can be made for projected changes in seasonal temperature means, showing a higher winter warming rate by up to $0.5^{\circ} \mathrm{C}$, as compared to other seasons. However, projected changes in seasonal precipitation means, obtained with the help of individual models, do largely differ and are sometimes inconsistent. They exhibit spatial variations, depending on the future horizon, the emission scenario, as well as the season and the location of interest. The overall range of the $90 \%$ confidence interval predicted by the ensemble of multi-model simulations was found to vary in the range between 7\% (in summer, under RCP4.5) and $40 \%$ (in winter, under RCP8.5), for far future projection horizon (Mezghani et al. 2017).

Although seasonal precipitation was projected to increase considerably in all four combinations of RCPs and projection horizons for winter and spring, the model spread was quite high, especially for the remote future. In contrast, the ensemble members agreed that summer and autumn precipitation is not likely to undergo statistically significant changes. It is important to note that regional climate models were used to downscale a small number (four for RCP4.5) of GCMs, and that even one single GCM can produce very different local and regional projections due to the presence of pronounced nondeterministic natural variability on decadal timescales (Deser et al. 2012). Hence, estimates based on a small set of climate model simulations are subject to the "law of small numbers" (Benestad et al. 2017), for which the estimates may be misleading, the true range underestimated and the real uncertainties appear to be smaller than they really are.

Mezghani et al. (2018) tested the influence of selecting a subset of global climate models to drive two downscaling strategies (Empirical-Statistical and Dynamical Downscaling, i.e., ESD and DD, respectively) on the resultant regional and local climate information. As the method of dynamical downscaling is highly demanding and expensive, climate modelers typically run a small set of simulations instead of downscaling a large ensemble (like CMIP5 simulations). Mezghani et al. (2018) found that selecting a subset of GCMs in downscaling (EURO-CORDEX simulations) has an impact on the magnitude of the estimated signal. Results over Poland show that taking a small subset of GCMs to drive regional climate models leads to a significant reduction in the spread of future climatic changes, especially for precipitation, while the ensemble mean remains less affected. Both approaches, ESD and DD, showed similar tendencies of change signal for the near future but disagreed in projecting changes for the far future.

Piniewski et al. (2017b) examined projections of future changes in temperature and precipitation in the drainage basins of two large rivers, the Vistula and Odra/Oder (VOB), covering $88 \%$ of the Polish territory and also smaller areas in five Poland's neighbor countries (Czech Republic, Slovakia, Ukraine, Belarus, and Germany). Results were similar to those obtained by Mezghani et al. (2016) that spanned over the whole territory of Poland. Piniewski et al. (2017b) found that changes in annual mean of daily minimum and maximum temperature were fairly robust among models. These values were projected to increase by $1-1.5^{\circ} \mathrm{C}$ in the near future and by $1.8-3.7^{\circ} \mathrm{C}$ in the remote future (areal-means of the ensemble median values), depending on the emission scenario. Higher increases were consistently associated with minimum temperature. The lowest and highest increases were projected in SW and NE Poland, respectively. Seasonal projections of both minimum and maximum temperature were found to be less robust. Future warming in winter was projected to be higher than in other seasons, in particular for the remote future under the RCP8.5 scenario. However, projected changes in annual precipitation totals were highly uncertain, even though the climate models agreed on the increase. The mean multi-model increase ranged from 5.5\% in the near future under RCP4.5 to $16.2 \%$ in the remote future under RCP8.5.

Pińskwar and Dobler (2018) examined projected changes in heavy precipitation in Poland, carrying out analysis for annual and seasonal data. The examined indices were: number of days with intense precipitation (in excess of $10 \mathrm{~mm}$ per day), as well as 95th and 99th percentiles of daily precipitation. The number of days with heavy precipitation was shown to increase for both annual and seasonal data, in particular during spring and summer. Trends detected for all stations showed increases for winter and spring. Also, the 95th and 99th percentiles of precipitation increased for annual data, while the highest seasonal increase for the 99th percentile was found during winter and spring. Generally, increases in extreme precipitation were projected in all seasons, time horizons and scenarios. The increases grew from the near to the far future and from RCP4.5 to RCP8.5.

Szwed et al. (2018) examined the projections of maximum snow cover depth in Poland for near and remote future, under two emission scenarios (RCP4.5 and RCP8.5). The bias-adjusted daily temperature and precipitation projections (Mezghani et al. 2017) were used as the input data 
to the seNorge (www.seNorge.no) snow model to generate future daily snow conditions. Projections suggest that the maximum snow depth may decrease by both future horizons of relevance and under both RCPs. This rate of decrease is expected to be about $15 \%$ and $20 \%$, assuming the RCP 4.5 and RCP8.5 emission scenarios, respectively, for near time horizon, as compared to the reference dataset. Overall, the rate of decrease could even double by the far future, regardless of the emission scenario and may go down to more than $40 \%$ when assuming the high emission scenario RCP8.5. Nevertheless, even if most areas in Poland are expected to get affected, changes in central regions are less pronounced.

\section{Climate change impacts}

\section{Trend detection in river discharge}

Piniewski (2017) analyzed classification of natural regimes of river discharge in Poland. Piniewski et al. (2018a) examined long-term trends in values of selected observed discharge indices in small- and medium-sized, near-natural catchments (with relatively unmodified flow regime) in Poland, over two time intervals (1956-2016 and 1981-2016). Geographical coverage of this study can be rated as adequate, while some regions with less human impact (such as NE Poland) have a relatively stronger representation. Piniewski et al. (2018a) examined changes in indices describing annual and seasonal average conditions as well as annual extremes-low and high discharges. The special focus was on the spatial analysis of trends, on the basis of a comprehensive, representative, river flow record in Poland. Piniewski et al. (2018a) filled a substantial gap existing in the scientific literature, because there have been no earlier studies on trend detection in observed discharge records covering the entire country or its large parts, carried out for recent data. The results of Piniewski et al. (2018a) suggest that a strong random (or natural variability) component exists in the river discharge process. The detected changes are rather weak and their spatial pattern is complex. For both studied periods of observation records and for two subsets of stations (providing a longer time series of records at fewer stations and a shorter series at more stations), negative trends in mean annual river discharge were found to prevail. Yet, the results of trend detection in values of various indices of river discharge in Poland demonstrated the existence of a spatial divide that seems to hold quite generally for different analyses-for annual, seasonal, as well as low and high discharge records. Decreases in river discharge dominate in the north of Poland and increases usually dominate in the south, while stations in the central belt of the country mostly do not show any trend. However, the spatial gradient is apparent only for the data for the shorter, more recent, interval (1981-2016) and not for the entire, longer, interval, 1956-2016, for which records are available. It seems that the magnitude of increases in river flow is generally lower than that of decreases. In contrast, for the longer time interval 1956-2016, no trends were identified for about half of the stations throughout Poland. It can be interesting to note that decreases in low flow were observed in areas where the mean river discharge is low already; hence, the streamflowdrought problems have likely been exacerbated there. It was found that some catchment properties correlate well with river discharge indices and the strongest predictor was the distance from the geographical center of the examined catchment to the Baltic Sea coast.

\section{Projections of river runoff}

Model-supported studies of projections of river runoff have been undertaken in many countries and regions of Europe in the framework of climate change impact assessment for the water sector (cf. Hattermann et al. 2011), yet such largescale studies have been very scarce in Poland. Piniewski et al. (2017a) assessed climate change impacts on spatiotemporal distribution of annual and seasonal runoff in the entire Vistula and Odra basins (VOB). They used the SWAT model, set up at high resolution and driven by a multi-model ensemble of nine bias-corrected EURO-CORDEX simulations under two representative concentration pathways (RCPs), 4.5 and 8.5. Piniewski et al. (2017d) illustrated the annual and seasonal runoff in the reference period as well as projections for the future, including the multi-model spread based on the agreement between models and statistical significance of change according to each model. Annual runoff increases were found to dominate, regardless of RCP and future horizon. The magnitude of the mean, spatially averaged, runoff was found to increase, meaningfully, by $15.8 \%$ (RCP4.5, near future) up to $41.6 \%$ (RCP8.5, remote future). The seasonal patterns indicate the highest increase in winter and the lowest in spring, whereas the spatial patterns show the highest increase in the inner, lowland part of VOB, and the lowest in the southern, mountainous, part. Accompanying projections of potential evapotranspiration estimated using the Hargreaves method implemented in SWAT suggested modest ensemble mean increase, ranging from $2.9 \%$ for RCP 4.5 in the near future to $8.8 \%$ for RCP 8.5 in the far future (Piniewski et al. 2017d).

Piniewski et al. (2017a) compared the projections of mean annual and mean seasonal river runoff obtained with the help of the SWAT model with projections derived with the help of the lumped, conceptual, HBV model, for eight catchments in Poland, of small and medium size. Although increases in mean discharge indices were projected in both studies, the magnitudes of changes were largely different, in particular for the lowland catchments and especially in 
the remote future. In the latter case, the SWAT-projected increases were significantly lower than the HBV-projected increases in all seasons, except for winter. Thus, uncertainty in river flow projections was found to be high and this creates a serious challenge for practitioners. Work on hydrological model inter-comparison should be continued, so that the mechanisms responsible for differences in hydrological projections in Poland derived using different models are better understood and interpreted.

\section{Water quality}

Two mesoscale models were calibrated and used, for two medium-sized lowland catchments in Poland, the Barycz and the Upper Narew (which are subcatchments of the VOB), for nitrogen, phosphorus and sediment load assessments and projections (Marcinkowski et al. 2016, 2017). These catchments represent two important categories of conditions characteristic for the Polish Plain: a higher human pressure on water resources in the West (Barycz) and a lower pressure in the East (Upper Narew). Projections of the amount of total nitrogen (TN) and total phosphorus (TP) losses and of sediment that is transported from land areas to the stream network were derived, using the same climate model dataset as in Piniewski et al. (2017a), but only for the RCP4.5 scenario. Ensemble median in TN losses for the Barycz catchment in the remote future was projected to increase by $35 \%$, whereas an even stronger increase, by $45 \%$, was projected for the Upper Narew basin. Projections of TP losses indicate moderate increases for the Upper Narew catchment, whereas there is high uncertainty for the Barycz catchment. A strong correlation was found (Marcinkowski et al. 2016, 2017) between the river runoff and TN load (in particular nitrates), related to high mobility of nitrates that are not assimilated by plants during the dormancy season, but rather transported to streams via subsurface flow. These processes are favored especially in winter and spring, when evapotranspiration is typically low and infiltration can be fairly high due to snowmelt.

\section{Floods and droughts}

Climate extremes tend to have considerable impact on sectors (cf. Hanson et al. 2007). In Poland, several destructive floods and extensive droughts have occurred in the last three decades (for example: floods in 1997, 2001 and 2010 and droughts in 1992, 1994, 2006, 2008, 2015 and 2018). As phrased by Milly et al. (2008, 2015), "stationarity is dead," hence projections of high and low discharges are of considerable interest. They can play an important role in assessment and reduction in flood and drought risk (e.g., determination of a 100-year flood or a 100-year drought). Piniewski et al. (2017e) developed projections of high and low river discharges in the VOB. Despite a substantial spread of the resultant projections, the principal finding was that increases in both high and low discharges are likely to dominate in the future (Fig. 2). The magnitude of increase in low discharge was found to be considerably higher than that of high discharge, that is, future streamflow droughts were projected to be less severe, whereas, in contrast, river floods were projected to increase. This latter change is likely to exacerbate a challenge for river flood risk reduction, water management, and climate change adaptation. Piniewski et al. (2017e) also took a broader perspective, presenting a review of projections of high and low discharges in Central and Eastern European river basins reported in the literature, and unveiling uncertainty. However, they noted an overall qualitative agreement of their findings for the VOB region with projections of hydrological extremes from large-scale models forced by EURO-CORDEX results in the European-scale studies.

Kundzewicz et al. (2017g) examined observed and projected changes in flood hazard in Europe. They analyzed spatial and temporal variability of large floods, using a time series of flood-related information for 1985-2016, collected by the Dartmouth Flood Observatory (USA). They noted that it is difficult to disentangle the climatic change component from strong natural variability and direct human impacts. The climate change impact on river flood hazard in Europe is complex and depends on the flood generation mechanism. No ubiquitous, spatially consistent, changes in flood hazard characteristics in observation records have been detected, so far. However, Kundzewicz et al. (2017g) found an increasing tendency in the number of observed floods with large magnitude and severity in Europe, even if the year-to-year variability was strong.

Kundzewicz et al. (2017e, g) found considerable differences in a set of studies of flood hazard projections in Europe and tried to interpret them. They noted a considerable spread of projections among studies reported in the academic literature, carried out under different assumptions. Therefore, caution must be exerted by practitioners when trying to interpret conflicting pieces of information on flood hazard projections, stemming from different sources.

Wyżga et al. (2018) examined various approaches to river flood risk reduction in the region of the Upper Vistula Basin, demonstrating that nature-based methods can lend themselves well to extend the traditional, structural, flood defense strategy. The work by Wyżga et al. (2018) extends the scope of the FLORIST project (Kundzewicz et al. 2014, 2017h), carried out for the northern foothills of the Tatra Mountains.

\section{Environment}

In accordance with the projections that showed a prevailing increase in annual and seasonal runoff, as well as in low and high flows in the majority of rivers in the VOB, 


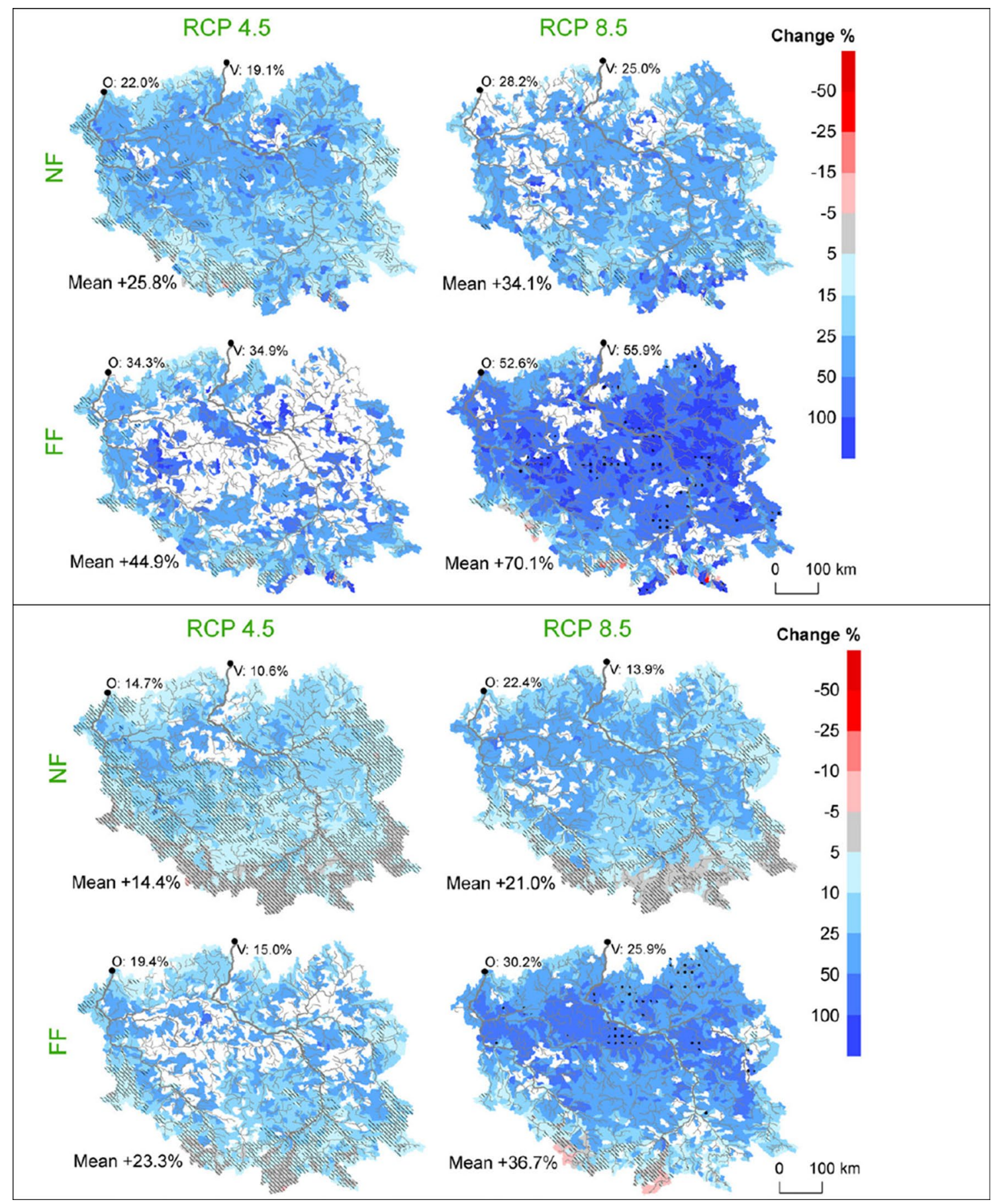

Fig. 2 Changes in low flow indicator-daily Q90 (top) and in high flow indicator-daily Q10 (bottom) Source: Piniewski et al. (2017e, by permission), modified

other hydrological variables such as inundation frequency and soil moisture content in selected groundwater-fed wetlands were also projected to be on the rise in the future climate (Kundzewicz et al. 2017a, b). The rate of increase was found to be typically higher for the far future than for the near future, and higher for RCP8.5 than for RCP4.5. An overall conclusion was that in-stream and riparian biota would face a new norm in their habitats. Projected changes in soil moisture for groundwater-fed wetlands suggest that their abiotic conditions are not likely to change significantly. The changes in high flows as well as in soil moisture content obtained with the help of models forced by rainfall and temperature projections for changing climate suggest that wetlands which are well adapted to wet conditions should 
be the least affected ecosystems. However, potential increase in soil moisture or in frequency of flooding may initiate the biological and ecological processes of changes in the wetland. Research on this topic is especially important in Natura 2000 special areas of conservation, where the current status of habitats is protected.

Derived projections suggest that the future climate will cause significant alterations in streamflow conditions important for migration and spawning of northern pike (Esox lucius), chub (Squalius cephalus) and Atlantic salmon (Salmo salar) in the VOB (O'Keeffe et al. 2018). Atlantic salmon, which is a species migrating long distances to spawn, is under the highest impact. Increased streamflow during spawning migration (September-October), along with the increased number and duration of low pulses, may cause deceptive spawning cues and impact the breeding success by suspending or reducing the number of spawning individuals. The projected increase in streamflow during spawning (November-December) and rising duration of high pulses could contribute to washing out eggs and alevins mortality. Chub prefers high flows for spawning and is slightly affected by flooding thus increase in the median duration of low pulses could be harmful to this fish but the increased flow in the spring might be beneficial. Furthermore, increased spring flows might impact the spawning success of northern pike. As this species deposits eggs in flooded areas, this can impact northern pike in a dual way. Either it can increase days with floodplain inundation and connectivity which would be advantageous for the species or cause an abnormal high streamflow or flash floods that could wash away the fish. Northern pike favors little variability in flow and, in the conditions of climate change, a fluctuation between low and high flows could become more rare.

Whether those fish will be able to adapt, considering the speed of changes projected to occur, is uncertain. Projecting impact of climate change on fish is a pressing matter, and the study of O'Keeffe et al. (2018) allowed to get a glimpse into what might happen when streamflow conditions important for migration and spawning are altered.

\section{Agriculture}

Agricultural sector in Poland is of high social and economic importance and the number of professionally active population in agriculture in Poland is higher (both in absolute and relative terms) than in any other country of the European Union. Since agriculture strongly depends on climatic conditions, the observed and projected climate change raises considerable interest and concern in the sector. Kundzewicz and Kozyra (2017) tackled climate change impacts on agriculture in Poland, both in the context of past observations (where strong inter-year variability is evident) and modelbased projections for the future. Climate changes, and in particular increases in temperature and changes in rainfall, have strong impacts on agriculture notably via weather extremes-droughts and heat waves as well as heavy precipitation and do indeed significantly affect crop growth.

Marcinkowski and Piniewski (2018) examined the impact of climate change on sowing and harvesting dates of selected crops in Poland. They found that projected warmer climate considerably affects scheduling of agricultural practices, accelerating sowing and harvesting dates across the entire country. The acceleration rate is strongly dependent on the future time horizon of concern and the RCP scenario, and the highest advancement is projected for far future under RCP8.5, reaching 23 and 30 days, for spring barley and maize, respectively. Evidence shows that soil moisture anomalies (deficits or excesses) are the key factor affecting crop growth in rain-fed agriculture, dominating in the country. In recent decades, major soil moisture anomalies have been recorded, leading to severe crop failures. Piniewski et al. (2018b) simulated multi-annual variability of soil moisture anomalies in Poland and assessed the effect of climate change on extreme soil moisture conditions in the future, that can adversely affect crop yields. A crop-specific (winter cereals, spring cereals, potato and maize) indicator based on simulated daily soil moisture content during the crop development stages with critical soil moisture requirements) was designed, evaluated for the past conditions against empirical crop-weather indices and applied for studying future climate conditions. For spring cereals, potato and maize, despite a large model spread, projections generally showed increasing severity of soil moisture deficits, as well as an increase in the total area affected by them. The signals of change in soil moisture excesses for potato and maize largely depended on selection of RCP and future horizon.

\section{Heat waves and mortality}

Graczyk et al. (2018) examined mortality triggered by heat waves in Poland. They estimated a likely number of additional fatalities in 10 largest cities of Poland, recorded during, and immediately after, heat waves in particularly hot summer seasons. Since 1989, four summer seasons with intense, long-lasting, heat waves occurred in 1992, 1994, 2006 and 2010, with a considerable increase in the number of deaths in the largest towns in the country. The numbers of fatalities in heat wave days and some interval afterward were compared to the numbers of fatalities in the same calendar days in reference years without heat waves. An increase in mortality risk for people over 65 years of age and for those with cardiovascular deficiencies was noted. The total number of additional fatalities related to heat waves could have exceeded a thousand in 1994. During the hottest days in the analyzed period, in some cities, the number of fatalities was 
more than three times higher than the mean value for the reference period.

In the scientific literature related to mortality increase due to heat waves, it is often underlined that densely populated areas are at the highest risk. Nevertheless, since increase in mortality during heat waves can occur in smaller towns and in rural areas, the number of additional fatalities in the entire Poland is likely to be considerably higher.

The results of Graczyk et al. (2018) indicate that the increase in mortality related to heat waves is a serious threat in Poland already in the present climate and is likely to be even more severe in a future "warmer" climate. If climate model projections come true, then the most tragic heat wave in Poland, that took place in 1994, will be more commonplace in the coming decades. The "load" is increasing, because heat waves get more intense and last longer, while the "resistance" is decreasing because the number of aged people in the Polish society is growing fast.

\section{Uncertainty and perception}

The scientific evidence related to climate change and its attribution, impacts and possibilities of mitigation has been dynamically increasing. Yet, "climate change contrarianism" persists in many countries, rhyming with the observed general crisis of confidence to scientists and the triumphal advent of alternative post-truth realities, wherein discourse is framed largely by appeals to emotion disconnected from facts. This general tendency can be noted in many countries, including Poland and Norway, that is countries collaborating in the CHASE-PL project- that are fossil fuel giants with vocal contrarians, cf. Kundzewicz et al. (2017c) and Ceglarz et al. (2018). The public discourse in Poland, related to energy issues, concentrates to a large extent on the energy independency and security that are grounded on the rich domestic coal deposits, whereas the environmental dimension of the energy policy is conveniently downplayed. The access to the domestic fossil fuels is believed to ensure a regular economic development and low electricity price. It is also an argument for less interest in developing renewable energy sources in Poland. Most politicians, backed by the media and the coal and energy industry, explicitly undermine the scientific evidence of climate change.

Climate change and climate change impact studies would be incomplete without consideration of uncertainties that are plentiful in understanding, observations and projections, as well as the issues of perception. Three related uncertainty aspects of particular relevance can be distinguished: identification of uncertainty sources, quantification of uncertainty components, and devising a framework for uncertainty reduction. The concepts of uncertainty play a prominent role in the research on global environmental change. We are uncertain about the future, but also- to some extentabout the recorded history and even the present. Kundzewicz et al. (2018) reviewed the use of the uncertainty notion to process understanding and modeling of systems, detection of change in observation records, and-foremost-projections of climate change impact on water resources for future time horizons. They presented a framework of proposing and assessing measures that could improve uncertainty communication, by relying on model ensembles and multi-model probabilistic approaches. Kundzewicz et al. (2018) distinguished two management strategies for the case of irreducible uncertainty - the precautionary principle and the adaptive management.

Kundzewicz et al. (2017d) discussed the challenges for developing national climate services in two countriesPoland and Norway, whose fossil fuel production is high. Poland is a major producer of coal while Norway-of oil and gas. In both countries, weather services are advanced, but the stages of development of climate services are largely different. In Norway, where downscaling of climate models commenced more than 20 years ago, tailored climate change projections have been made available to the broad society. Now, climate services are well developed-the Norwegian Centre for Climate Services (NCCS) has been operating since 2011. In contrast, climate services in Poland actually do not exist and this is not an exception among countries of Central and Eastern Europe. Many countries in the region neither have their national climate services nor are interested in European climate services enhanced via EU initiatives. The information generated within the CHASEPL project, that has been broadly disseminated in Poland, could be regarded as a temporary (extending over the project duration) substitute for the kind of information that in other countries is delivered to the society by national climate services.

\section{Generated datasets}

In order to prepare the basis for water-related impact studies, Piniewski et al. (2017d) applied the SWAT (Soil Water Assessment Tool) model in the entire Vistula and Odra basins (VOB), in order to assess the water balance and simulate natural streamflow. Since these basins include parts of five Poland's neighbor countries, the study has an international relevance. This was quite a large task, because modelbased high-resolution analysis for the whole river basins of the Vistula and the Odra has never been conducted in Poland before. The CHASE-PL forcing data—gridded daily precipitation and temperature dataset-5 km (CPLFD-GDPT5) that consisted of daily minimum and maximum air temperatures and precipitation totals, for the control interval, 1951-2013, interpolated onto a $5-\mathrm{km}$ grid based on daily meteorological 
observations (Berezowski et al. 2016) was used as driving climate dataset. A multi-site calibration approach allowed to achieve satisfactory goodness-of-fit across a range of catchment sizes and types. Model calibration and evaluation, driven by high-resolution climate data, showed satisfactory overall behavior for 80 benchmark catchments divided into eight clusters. The spatial evaluation performed for 30 gauges led to the conclusion that the designed parameter regionalization scheme performed quite well, with the median value of Kling-Gupta efficiency (KGE) of 0.76 . The study by Piniewski et al. (2017d) can serve as a basis for work on projections of climate change impacts on water resources and their management, assessing flow alterations, agriculture and environment. The model output dataset (CHASE-PL natural hydrology, CPL-NH) is publicly available as an online research data archive (https://data.4tu.nl/ repository/uuid:b8ab4f5f-f692-4c93-a910-2947aea28f42).

Mezghani et al. (2016) compiled and published the CHASE-PL climate projections_-gridded daily precipitation and temperature dataset-5 km (CPLCP-GDPT5), consisting of projected daily minimum and maximum air temperatures and precipitation totals. This high-resolution bias-corrected product can serve as a basis for climate change impact and adaptation studies for selected sectors in Poland.

The CHASE-PL project provided open access datasets for researchers. This included forcing data for environmental models (historical, observation-based, for the interval 1951-2013) and model-based projections for two future time horizons: 2021-2050 and 2071-2100, as well as SWAT simulations: water balance and streamflow in the historical control interval and future horizons. The data are available in open access at online data repository-4TU Centre for Research Data https://data.4tu.nl/ repository/ (or Google search: CHASE-PL data). Selected data were published in high-impact, open access, data journals (Berezowski et al. 2016; Mezghani et al. 2017). The dataset of model outputs based on all simulations, driven by the results of bias-corrected models in the EURO-CORDEX initiative (Mezghani et al. 2016), called CHASE-PL-future hydrology (CPL-FH), is also publicly available (Piniewski et al. 2017f).

The datasets produced within the project are freely available for research purposes. When reusing the data, one should clearly refer to the name(s) of the original author(s). Yet, for commercial purposes, no free use of data is guaranteed.

Within the CHASE-PL project, a geoportal was developed at the Warsaw University of Life Sciences (SGGW) under the leadership of Ignacy Kardel (Fig. 3). This interactive web-mapping system (http://climateimpact.sggw.pl) provides spatial, interactive, visualization of observed and projected climate change and its impact on selected sectors in Poland. The geoportal was awarded a prize in the Internet

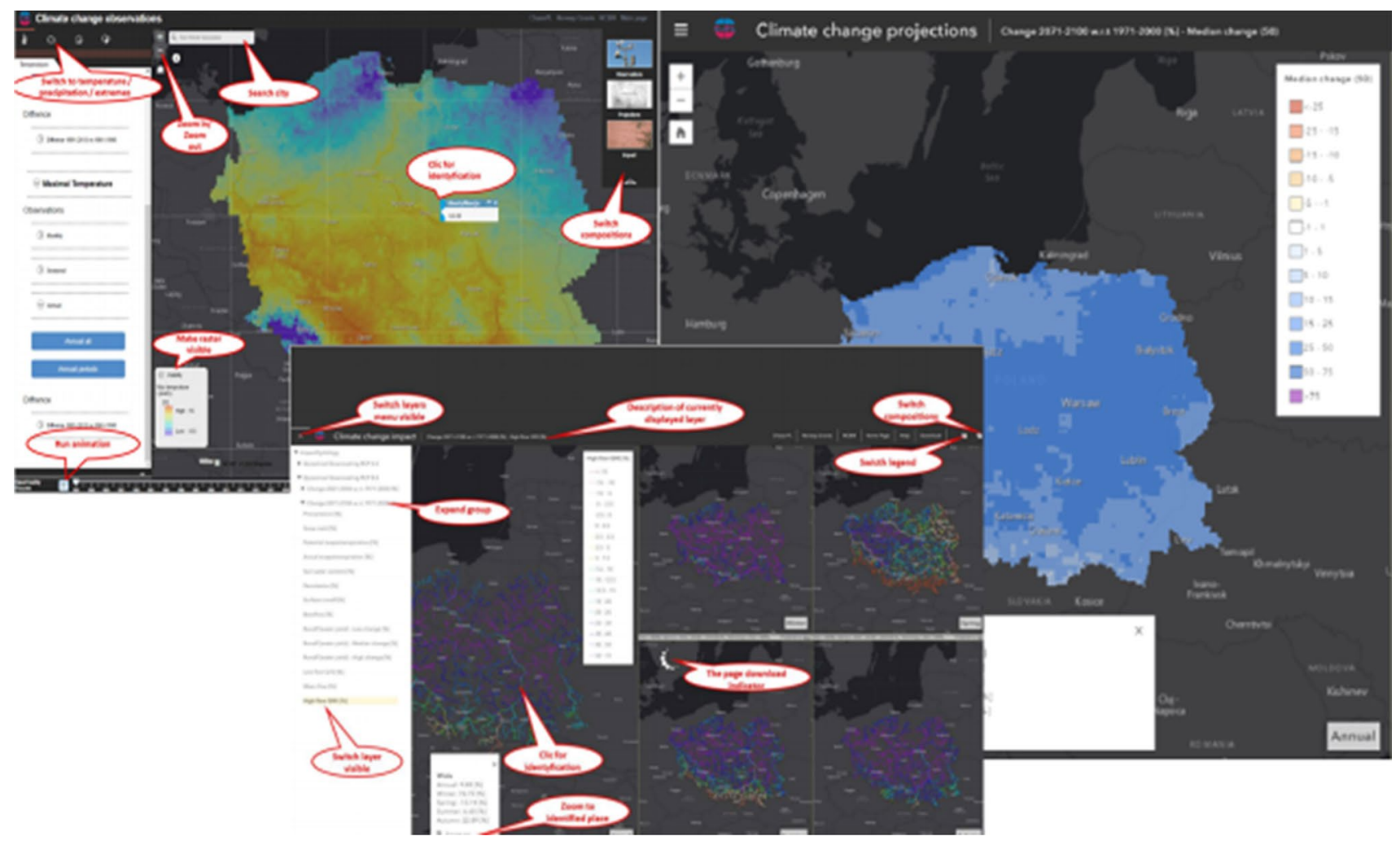

Fig. 3 A sample of screenshots from the climate change geoportal, created within the CHASE-PL project (http://climateimpact.sggw.pl) 


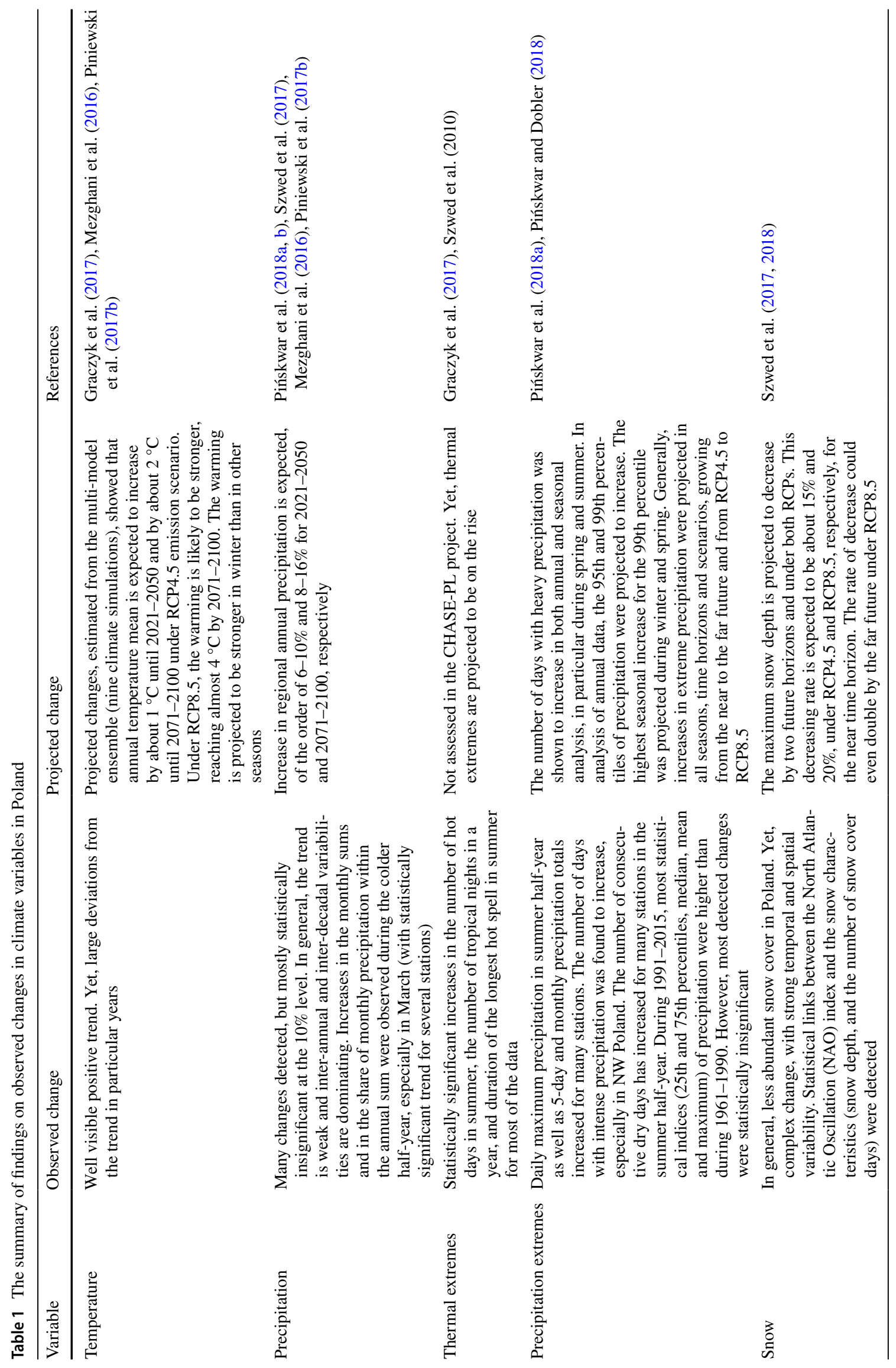




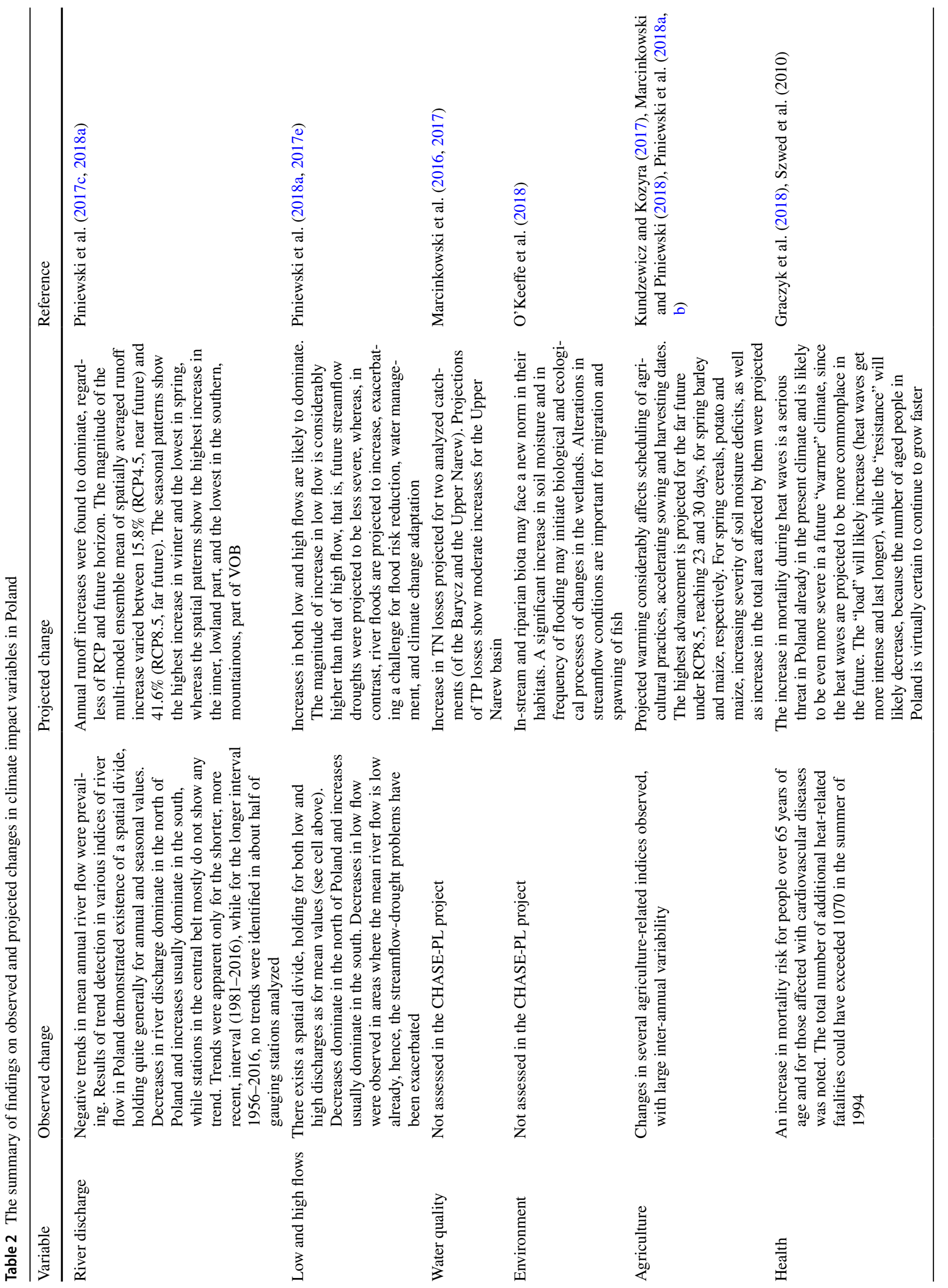


Fig. 4 Cover of the monograph, in English and in Polish, summarizing the results of the CHASE-PL project (Kundzewicz et al. 2017a, b)

ZBIGNIEW W. KUNDZEWICZ TOMASZ OKRUSZKO (EDS)

TOMASZ OKRUSZKO (EDS.)

Climate change and its impact on selected sectors in Poland.

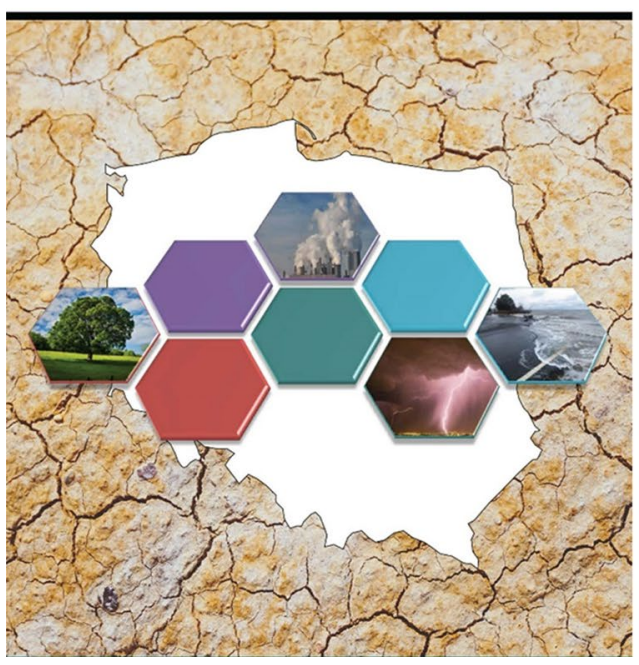

ZBIGNIEW W. KUNDZEWICZ

ØYSTEIN HOV

TOMASZ OKRUSZKO (RED.)

Zmiany klimatu i ich wpływ na wybrane sektory w Polsce

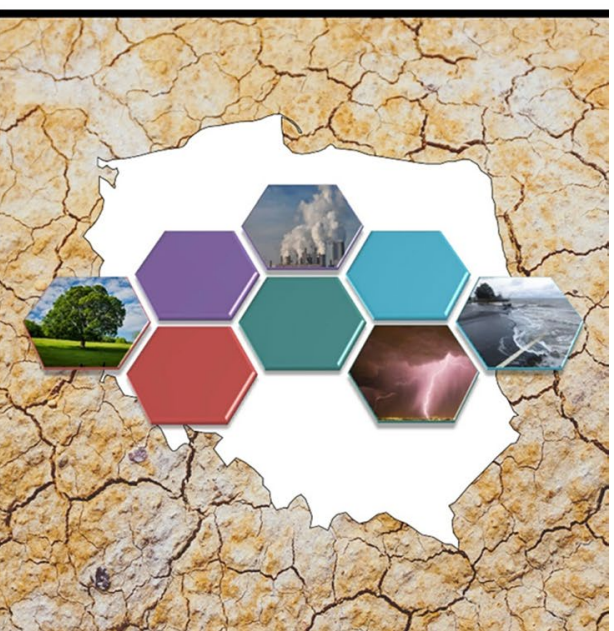

Map of the Year contest, 2016/2017, organized by the Society of Polish Cartographers.

The information contained in the geoportal enables other researchers to use project results in their own studies on climate change and climate change impact. The co-authors of this paper believe that free and easy access to processed historical data as well as projections enhances further work, hence contributing to better understanding and interpretation of climate change and associated impacts in Poland.

\section{Discussion and conclusions}

Tables 1 and 2 illustrate the summary of CHASE-PL project's findings on observed and projected changes in climate variables, as well as in climate impact variables, respectively.

The co-authors of this paper, who participated in the Polish-Norwegian CHASE-PL project trust that the project results contributed, in a considerable way, to improvement of understanding and interpretation of climate change impacts in such sectors, as: water resources, natural hazard risk reduction, health, agriculture and environment of Poland. It extended the state-of-the-art of the detection of change, projection of climate change and its impacts, as well as interpretation of uncertainty, and could contribute to improving general awareness. Planned project's objectives have been fully achieved and, actually, largely exceeded. Scientific outputs comprise: a book in Polish and English (Kundzewicz et al. 2017a, b), cf. Fig. 4, and many journal papers, some of which are listed in references overleaf, generation of scientific data, and development of a climate change geoportal.

The CHASE-PL project linked strengths of scientists from both participating countries: Norway's traditions and achievements in climate research and Poland's expertise in climate impact research. Norwegian partners provided common climatic foundations by producing downscaled projections, while Polish partners took the lead in impact research. The CHASE-PL project scientists made an attempt to bring the activities of the climate impact and the climatology communities closer together. This helped reduce the traditional, disciplinary, "disconnect" between communities developing assessment and modeling frameworks for impact studies (e.g., related to water resources) and the communities developing climate modeling frameworks.

Valuable inputs were also obtained from co-authors from beyond the project, as documented in several references listed overleaf.

The lessons learned from climate change impact studies, applying the CHASE-PL information, can help in shaping adaptation strategies and rising awareness of importance of this area in Poland.

The project contributed to reduction in the knowledge gap on climate change and associated impacts among the policymakers, stakeholders and the broad Polish society. It can be viewed as the substitute for national climate services that do not exist in Poland, even if the process updating the information was discontinued after the project end in April 2017. 
Acknowledgements The CHASE-PL (climate change impact assessment for selected sectors in Poland) project was funded in the framework of the Polish-Norwegian Research Programme under the Norwegian Financial Mechanism 2009-2014 (Project Contract No. Pol Nor/200799/90/2014) is gratefully acknowledged. The Alexander von Humboldt Foundation and the Polish Ministry of Science and Higher Education supported Mikołaj Piniewski. Finally, the Institute of Meteorology and Water Management-National Research Institute (IMGWPIB) provided the meteorological and hydrological data used in this study.

Open Access This article is distributed under the terms of the Creative Commons Attribution 4.0 International License (http://creativeco mmons.org/licenses/by/4.0/), which permits unrestricted use, distribution, and reproduction in any medium, provided you give appropriate credit to the original author(s) and the source, provide a link to the Creative Commons license, and indicate if changes were made.

\section{References}

Benestad R, Parding K, Dobler A, Mezghani A (2017) A strategy to effectively make use of large volumes of climate data for climate change adaptation. Clim Serv 6:48-54. https://doi.org/10.1016/j. cliser.2017.06.013

Berezowski T, Szcześniak M, Kardel I et al (2016) CPLFD-GDPT5: high-resolution gridded daily precipitation and temperature dataset for two largest Polish river basins. Earth Syst Sci Data. http:// www.earth-syst-sci-data.net/8/127/2016/. Accessed 2 Nov 2018

Ceglarz A, Benestad R, Kundzewicz ZW (2018) Inconvenience vs. rationality. Reflections on different faces of climate contrarianism in Poland and Norway. Weather Clim Soc (American Geophysical Union). https://doi.org/10.1175/WCAS-D-17-0120.1

Deser C, Knutti R, Solomon S, Phillips AS (2012) Communication of the role of natural variability in future North American climate. Nat Clim Change 2:775-779. https://doi.org/10.1038/nclimate15 62

Graczyk D, Pinskwar I, Kundzewicz ZW et al (2017) The heat goes onchanges in indices of hot extremes in Poland. Theor Appl Climatol 129(1-2):459-471

Graczyk D, Kundzewicz ZW, Choryński A et al (2018) Heat related mortality during hot summers in Polish cities. Theor Appl Climatol. https://doi.org/10.1007/s00704-018-2554-x

Hanson CE et al (2007) Modelling the impact of climate extremes: an overview of the MICE project. Clim Change 81:163-177. https:// doi.org/10.1007/s10584-006-9230-3

Hattermann FF et al (2011) Model-supported impact assessment for the water sector in Central Germany under climate change-a case study. Water Resour Manag 25(13):3113-3134. https://doi. org/10.1007/s11269-011-9848-4

Kundzewicz ZW, Matczak P (2012) Climate change regional review: Poland. Wiley Interdiscip Rev Clim Change 3(4):297-311

Kundzewicz ZW, Kozyra J (2017) Climate change impact on Polish agriculture. In: Kundzewicz ZW, Hov Ø, Okruszko T (eds) Climate change and its impact on selected sectors in Poland. Ridero IT Publishing, Poznań, pp 158-171. ISBN 978-83-8104-735-7

Kundzewicz ZW et al (2014) Floods at the northern foothills of the Tatra Mountains: a Polish-Swiss research project. Acta Geophys 62(3):620-641

Kundzewicz ZW, Hov $\varnothing$, Okruszko T (eds) (2017a) Climate change and its impact on selected sectors in Poland. Ridero IT Publishing, Poznań

Kundzewicz ZW, Hov Ø, Okruszko T (eds) (2017b) Zmiany klimatu i ich skutki w wybranych sektorach w Polsce. Poznań
Kundzewicz ZW, Benestad RE, Ceglarz A (2017c) Perception of climate change and mitigation policy in Poland and Norway. In: Kundzewicz ZW, Hov $\varnothing$, Okruszko T (eds) Climate change and its impact on selected sectors in Poland. Ridero IT Publishing, Poznań, pp 216-244. ISBN 978-83-8104-735-7

Kundzewicz ZW, Førland EJ, Piniewski M (2017d) Challenges for developing national climate services: Poland and Norway. Clim Serv 8:17-25

Kundzewicz ZW, Krysanova V, Dankers R et al (2017e) Differences in flood hazard projections in Europe: their causes and consequences for decision making. Hydrol Sci J 62(1):1-14

Kundzewicz ZW, Painter J, Kundzewicz WJ (2017f) Climate change in the media: Poland's exceptionalism. Environ Commun. https ://doi.org/10.1080/17524032.2017.1394890

Kundzewicz ZW, Pińskwar I, Brakenridge GR (2017g) Changes in river flood hazard in Europe: a review. Hydrol Res. https://doi. org/10.2166/nh.2017.016

Kundzewicz ZW et al (2017h) Changes of flood risk on the northern foothills of the Tatra Mountains. Acta Geophys 65(4):799-807

Kundzewicz ZW, Krysanova V, Benestad RE et al (2018) Uncertainty in climate change impacts on water resources. Environ Sci Policy 79:1-8

Łupikasza E (2010) Spatial and temporal variability of extreme precipitation in Poland in the period 1951-2006. Int J Climatol 30:9911007. https://doi.org/10.1002/joc. 1950

Łupikasza E (2017) Seasonal patterns and consistency of extreme precipitation trends in Europe, December 1950 to February 2008. Clim Res 72:217-237

Marcinkowski P, Piniewski M (2018) Climate change effect on sowing and harvest dates of spring barley and maize in Poland. Int Agrophys 32:265-271

Marcinkowski P, Piniewski M, Kardel I et al (2016) Challenges in modelling of water quantity and quality in two contrasting meso-scale catchments in Poland. J Water Land Dev 31(X-XII):97-111. https ://www.degruyter.com/view/j/jwld.2016.31.issue-1/jwld-20160040/jwld-2016-0040.xml. Accessed 2 Nov 2018

Marcinkowski P, Piniewski M, Kardel I et al (2017) Effect of climate change on hydrology, sediment and nutrient losses in two lowland catchments in Poland. Water 9(3):156. http://www.mdpi. com/2073-4441/9/3/156. Accessed 2 Nov 2018

Mezghani A, Dobler A, Haugen JE (2016) CHASE-PL climate projections: $5-\mathrm{km}$ gridded daily precipitation and temperature dataset (CPLCP-GDPT5). Norwegian Meteorological Institute, Oslo. https://doi.org/10.4121/uuid:e940ec1a-71a0-449e-bbe3-29217 f2ba31d (Dataset)

Mezghani A, Dobler A, Haugen JE et al (2017) CHASE-PL climate projection dataset over Poland: bias adjustment of EURO-CORDEX simulations. Earth Syst Sci Data 9(2):905-925

Mezghani A, Dobler A, Benestad R (2018) Subsample effect on the climate change signal based on simulations from statistical and dynamical downscaling. J Clim (submitted)

Milly PCD et al (2008) Stationarity is dead: whither water management? Science 319:573-574

Milly PCD et al (2015) On critiques of "stationarity is dead: whither water management?". Water Resour Res 51(9):7785-7789. https ://doi.org/10.1002/2015WR017408

O’Keeffe J, Piniewski M, Szcześniak M, Oglęcki P, Parasiewicz P, Okruszko T (2018) Index-based analysis of climate change impact on streamflow conditions important for northern pike, chub and Atlantic salmon. Fish Manag Ecol. https://doi.org/10.1111/ fme. 12316

Piniewski M (2017) Classification of natural flow regimes in Poland. River Res Appl 33(7):1205-1218

Piniewski M, Meresa HK, Romanowicz R et al (2017a) What can we learn from the projections of changes of flow patterns? results from Polish case studies. Acta Geophys 65(4):809-827 
Piniewski M, Mezghani A, Szcześniak M et al (2017b) Regional projections of temperature and precipitation changes: robustness and uncertainty aspects. Meteorol Z 26(2):223-234

Piniewski M, Szcześniak M, Huang S, Kundzewicz ZW (2017c) Projections of runoff in the Vistula and the Odra river basins with the help of the SWAT model. Hydrol Res. https://doi.org/10.2166/ nh.2017.280

Piniewski M, Szcześniak M, Kardel I et al (2017d) Hydrological modelling of the Vistula and Odra river basins using SWAT. Hydrol Sci J 62(8):1266-1289

Piniewski M, Szcześniak M, Kundzewicz ZW et al (2017e) Changes in low and high flows in the Vistula and the Odra basins: model projections in the European-scale context. Hydrol Process 31(12):2210-2225

Piniewski M, Szcześniak M, Kardel I (2017f) CHASE-PL: future hydrology data set: projections of water balance and streamflow for the Vistula and Odra basins, Poland. Data http://www.mdpi. com/2306-5729/2/2/14. Accessed 2 Nov 2018

Piniewski M, Marcinkowski P, Kundzewicz ZW (2018a) Trend detection in river flow indices in Poland. Acta Geophys https://link. springer.com/article/10.1007\%2Fs11600-018-0116-3. Accessed 2 Nov 2018

Piniewski M, Marcinkowski P, O’Keeffe J et al (2018b) Model-based reconstruction and projections of soil moisture anomalies and crop losses in Poland. Agric For Meteorol (submitted)
Pińskwar I, Dobler A (2018) Observed and projected changes in heavy precipitation in Poland. Met Hydrol Water Manag (submitted)

Pińskwar I, Choryński A, Graczyk D, Kundzewicz ZW (2018a) Observed changes in extreme precipitation in Poland: 1991-2015 versus 1961-1990. Theor Appl Climatol. https://doi.org/10.1007/ s00704-018-2372-1

Pińskwar I, Choryński A, Graczyk D, Kundzewicz ZW (2018b) Observed changes in precipitation in Poland. Geografie (submitted)

Szwed M (2018) Variability of precipitation in Poland under climate change. Theor Appl Climatol. https://doi.org/10.1007/s0070 4-018-2408-6

Szwed M, Karg G, Pińskwar I, Radziejewski M, Graczyk D, Kędziora A, Kundzewicz ZW (2010) Climate change and its effect on agriculture, water resources and human health sectors in Poland. Nat Hazards Earth Syst Sci 10:1725-1737. https://doi.org/10.5194/ nhess-10-1725-2010

Szwed M, Pińskwar I, Kundzewicz ZW et al (2017) Changes of snow cover in Poland. Acta Geophys 65(1):65-76

Szwed M, Dobler A, Mezghani A, Saloranta TM (2018) Change of maximum snow cover depth in Poland. Idojaras (submitted)

Wyżga B, Kundzewicz ZW, Konieczny R et al (2018) Comprehensive approach to the reduction of river flood risk: case study of the Upper Vistula Basin. Science Total Environ 631-632:1251-1267. https://doi.org/10.1016/j.scitotenv.2018.03.015 